\title{
What Happens While Waiting in Virtual Reality? A Comparison Between a Virtual and a Real Waiting Situation Concerning Boredom, Self-Regulation, and the Experience of Time
}

\author{
Federico Alvarez Igarzábal ${ }^{1}$, Helena Hruby ${ }^{2}$, Joanna Witowska ${ }^{3}$, Shiva Khoshnoud ${ }^{1}$, and \\ Marc Wittmann ${ }^{1}$ \\ ${ }^{1}$ Institute for Frontier Areas of Psychology and Mental Health, Freiburg im Breisgau, Baden-Württemberg, Germany \\ ${ }^{2}$ Institute of Psychology, University of Freiburg \\ ${ }^{3}$ Department of Psychology, University of Warsaw
}

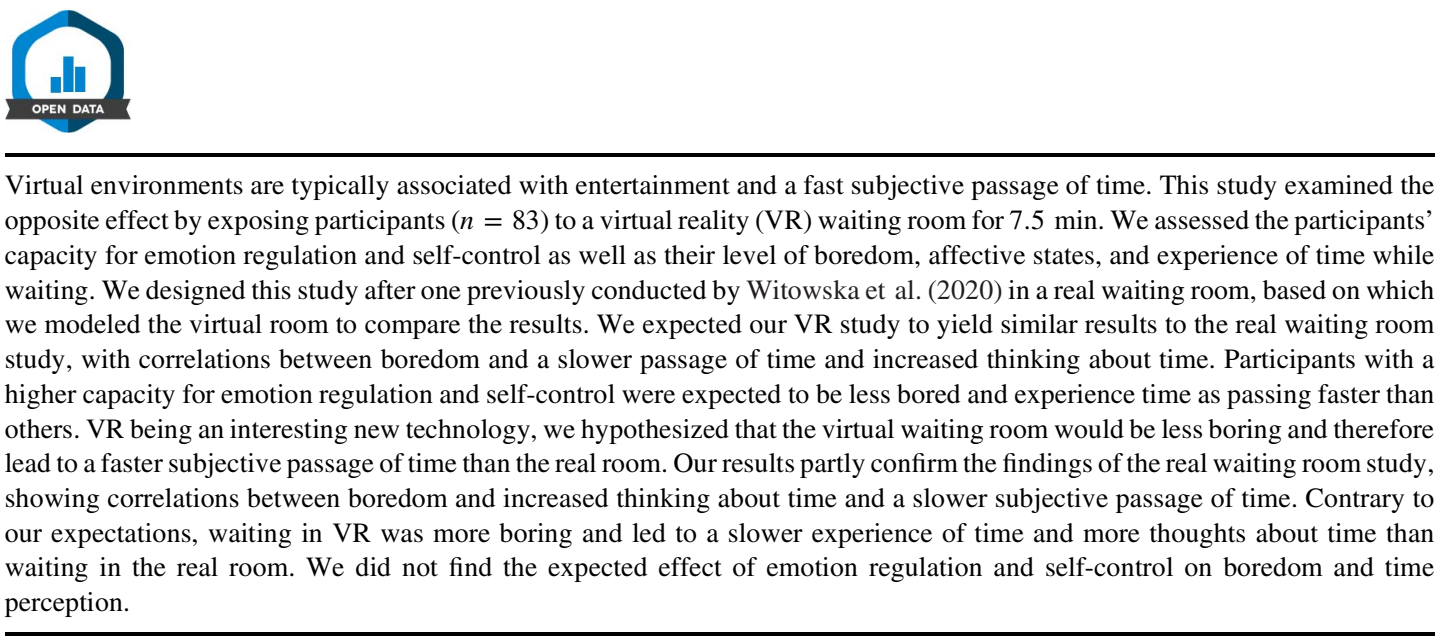

Keywords: virtual reality, time perception, self-regulation, boredom, waiting

Supplemental materials: https://doi.org/10.1037/tmb0000038.supp

Virtual environments are typically experienced in video games, which provide exciting challenges and captivating audiovisual stimuli designed to capture our attention. By getting hold of our attention, they accelerate the subjective passage of time. In a survey conducted by Wood et al. (2007), 99\% of respondents reported losing track of time while playing video games. A number of experimental studies also showed that we tend to underestimate the duration of a play session and experience a faster passage of time (Bisson et al., 2012; Bisson \& Grondin, 2013; Luthman et al., 2009; Rau et al., 2006; Rutrecht et al., 2021; Tobin et al., 2010;
Action Editor: C. Shawn Green was the action editor for this article.

ORCID iDs: Federico Alvarez Igarzábal (D) https://orcid.org/0000-00021335-5340; Joanna Witowska (D) https://orcid.org/0000-0002-9063-049X; Shiva Khoshnoud (DD https://orcid.org/0000-0002-0729-9717; Marc Wittmann (iD) https://orcid.org/0000-0002-4483-7334.

Some of the data have been used in a prior study, which is duly reported in the Method section. The authors have no conflicts of interest to disclose. This study was funded by the EU, Horizon 2020 Framework Program, FET Proactive (VIRTUALTIMES consortium, grant agreement Id: 824128 to Marc Wittmann). VIRTUALTIMES - Exploring and modifying the sense of time in virtual environments-includes the following groups with the principal investigators Kai Vogeley (Cologne), Marc Wittmann (Freiburg), Anne Giersch (Strasbourg), Marc Erich Latoschik, and Jean-Luc Lugrin (Würzburg), Giulio Jacucci and Niklas Ravaja (Helsinki), Xavier Palomer and Xavier Oromi (Barcelona).
Open Science Disclosures:

II The data are available at https://doi.org/10.17605/OSF.IO/3AKM7

Open Access License: This work is licensed under a Creative Commons Attribution-NonCommercial-NoDerivatives 4.0 International License (CC-BYNC-ND). This license permits copying and redistributing the work in any medium or format for noncommercial use provided the original authors and source are credited and a link to the license is included in attribution. No derivative works are permitted under this license.

Disclaimer: Interactive content is included in the online version of this article.

Contact Information: Correspondence concerning this article should be addressed to Federico Alvarez Igarzábal, Institute for Frontier Areas of Psychology and Mental Health, Wilhelmstraße 3a, Freiburg im Breisgau, Baden-Württemberg 79098, Germany. Email: alvarez@igpp.de 
Tobin \& Grondin, 2009; Wood et al., 2004). This relates directly to the mental state called flow (Alvarez Igarzábal, 2019; Csikszentmihalyi, 2009, 2014), which is characterized by deep absorption in an activity, a sense of control, and the loss of the senses of self and time (Wittmann, 2015, 2018).

When not in a state of flow or optimally challenged, on one end we experience anxiety when we are overchallenged, and on the other, boredom when we are underchallenged (Csikszentmihalyi, 2000). Both these states lead to the experience of a relative slower passage of time. Efforts in psychology have focused on studying the capacity of virtual environments (and mainly video games) to accelerate the subjective passage of time but, to our knowledge, there is still little research concerning the experience of the passage of time slowing down due to states antithetical to flow (anxiety or boredom) in virtual environments. The aim of the present study was to induce boredom in participants with a virtual reality (VR) waiting room situation to assess the relationship between boredom, time perception, and self-regulation. The study was conducted in the context of the VIRUALTIMES project, aimed at creating a VR environment to treat psychopathologies like depression and schizophrenia through the manipulation of time perception. Expanding our understanding of how virtual environments affect the subjective passage of time beyond its acceleration can offer valuable insights to those working at the intersection of VR, video games, and mental health.

The acceleration and deceleration of the passage of time in our experience is explained in psychology by pacemaker-accumulator models (Treisman, 2013; Treisman et al., 1990). The most prominent among these is the attentional-gate model proposed by Zakay and Block (1995, 1997), which postulates a pacemaker that fires pulses (a conceptual construct adopted already by Treisman). Whenever we pay attention to time, a gate opens that lets the pulses through, which are accumulated by a counter. The amount of accumulated pulses gives us the estimate of how much time has passed. Arousal can accelerate the pacemaker's rate, meaning that more pulses are fired and thus counted during emotionally charged events. This is why such events are judged as being longer than emotionally neutral ones (Angrilli et al., 1997; Bar-Haim et al., 2010; Droit-Volet et al., 2004; Gil et al., 2007; Pollatos et al., 2014; Tipples, 2008; Watts \& Sharrock, 1984). In addition, the more attentional resources are available, the wider the gate can open and the more pulses can pass through. Thus, paying attention to the passage of time leads to the overestimation of duration. This is especially the case when there is nothing of interest in our environment. Waiting rooms are the archetypal example of this situation. When sitting in expectation of a doctor's appointment, our attention is directed to time, the attentional gate opens more fully, and the passage of time slows down (Jokic et al., 2018; Witowska et al., 2020). But, when our attention is fully captured by an activity such as a video game, we have few resources left to attend to time and lose track of it. Whenever the activity is over and we become aware of time again, it seems to have passed exceedingly fast. This is typical of flow states.

Due to the impact of arousal in our experience of the passage of time, as explained by the attentional-gate model, self-regulation can help mitigate unwanted effects of the environment on time perception. Self-regulation is a trait that enables individuals to adjust their emotional states, temporal focus, and behavior (Isacescu et al., 2017; Witowska et al., 2020). According to Baumeister and
Heatherton (1996), there are three main components of selfregulation: Standards, which can be goals or desirable states; the monitoring of current states with relation to the standards; and a capacity to operate against an impulse to behave in a way that deviates from the standards. In this study, self-regulation will be used interchangeably with self-control, which is similarly defined in the literature (Baumeister et al., 2007; Hofmann et al., 2007). Being able to self-regulate emotional states allows individuals to avoid impulsive (present-focused) reactions and better control their own actions. Experiencing boredom causes us to direct our attention to time, slowing it down, and leading to overestimations of duration (Zakay, 2014; Zakay \& Block, 1997). Individuals who are better at self-regulating can cope better with boring situations. More impulsive individuals, in contrast, experience more boredom and a slower passage of time (Jokic et al., 2018; Wittmann \& Paulus, 2008).

Boredom can be defined as an "unpleasant, transient affective state, in which the individual feels a pervasive lack of interest" (Fisher, 1993, p. 396). One example of unintended boredom in a video game took place in the servers of World of Warcraft Classic (WoW Classic; Alvarez Igarzábal, 2020). In this game, players enter a digital fantasy world populated by thousands of other players and nonplayer characters. On launch day, WoW Classic servers filled up to the point that players had to queue and wait for their turn to complete some of the early missions. This led to prolonged waiting times and, presumably, boredom. It is likely that players in this situation started paying attention to time and experienced it as passing more slowly.

The few studies concerned with boredom in virtual environments are primarily focused on the physiological and neural markers of this emotion (Giakoumis et al., 2011; Mathiak et al., 2013). One preliminary study (Lugrin et al., 2019) showed that participants significantly overestimated the duration of a waiting period in an empty VR room with relation to a real waiting room in a condition without an avatar. In the VR condition with an avatar, the difference was not significant. This study only asked about the duration of the waiting period, while questions about how fast or slow time passed or how often participants thought about time were not asked. Moreover, due to its small sample size ( $n=15$ per condition), the results of this experiment are inconclusive.

A few studies are concerned with the passage of time in VR, but not specifically with boredom. A study conducted by Sucala et al. (2010) showed that participants enjoyed the interaction with a VR solar system application more when they were tricked into thinking that time passed fast and enjoyed it less when tricked into thinking that time passed slowly. To create this false sense of time passage, participants were told that they would play for $10 \mathrm{~min}$, while in reality one group played for 5 and the other for $20 \mathrm{~min}$. Duration estimation was also affected in a study that manipulated the speed at which the sun moved in a VR scene (Schatzschneider et al., 2016). VR has also been used to induce temporal recalibration by coupling the movement of individuals to the speed of events in the virtual environment (the slower participants moved, the slower the events unfolded and vice versa), which led to underreproduction of time intervals in a subsequent psychophysical task (Bansal et al., 2019). More in line with the objectives of this study, van der Ham et al. (2019) found no difference in the duration estimations of clips watched in a VR and in a real-life cinema, challenging the preconception that VR accelerates the passage of time. 
Emotion regulation is, as argued above, an advantageous trait to cope with boredom (Witowska et al., 2020), but we could find no studies concerned with this relation in the context of virtual environments. There are, however, studies that look at anxiety (the other antithetical flow state) in the context of video games aimed at helping children and adolescents cope with this emotion, as exemplified by the work of Isabela Granic and colleagues (Scholten et al., 2016; Schoneveld et al., 2016). A systematic review by Barnes and Prescott (2018) concludes that, although research is limited, video games show promising potential for the treatment of anxiety in adolescents. A further systematic review by Villani et al. (2018) shows that there is evidence from a variety of studies that video games can help individuals with emotion regulation, whether they were designed for that purpose or not. The mechanisms used to help enhance emotion regulation described by these reviews are diverse. Serious games designed for this purpose use cognitive behavioral therapy (CBT; Coyle et al., 2011; Scholten et al., 2016; Schuurmans et al., 2015) or a mixture of CBT and attention bias modification (ABM; Schoneveld et al., 2016). Commercial video games have been shown to help "alleviate and manage negative feelings" (Villani et al., 2018, p. 10) by functioning as a means of escapism through role play, presence and immersion in other worlds (Hussain \& Griffiths, 2009; Kuo et al., 2016), and time loss (Wood et al., 2007). Lobel et al. (2014) observed that in-game interoceptive awareness was positively related to the active implementation of regulatory strategies, hinting at the possibility that games could be used to train regulatory skills. The capacity of video games to provide a sense of control over the environment and satisfy the need for autonomy can also help players deal with negative emotions and consequently improve their mood (Bowman \& Tamborini, 2012; Ferguson \& Rueda, 2010; Reinecke et al., 2012; Rieger et al., 2014).

Attesting to the potential of VR to improve emotion regulation, VR Exposure Therapy (VRET) has been shown to help with phobias (Botella et al., 2017; Wechsler et al., 2019) and post-traumatic stress disorder (PTSD) (Deng et al., 2019). A study by Schneider et al. (2011) showed that VR can help cancer patients receiving chemotherapy, distracting them, and making the sessions seem shorter.

\section{The Present Study}

This study assessed the relation between boredom, selfregulation, and time perception in a virtual waiting room situation. The environment used was a VR version of a room at the Institute for Frontier Areas of Psychology and Mental Health (IGPP for its initials in German). The real room was used in a study conducted by Witowska et al. (2020) in which participants had to wait for 7.5 min without a smartphone or any other attention-grabbing devices. In our study, participants waited for the same amount of time in the VR room. To compare the results of both waiting situations, the design of our study was kept as close as possible to the design of the real waiting room experiment.

Witowska et al. (2020) did not tell their participants that they would be waiting during the experiment. Participants were welcomed to the institute and asked to hand over their belongings, such as bags, wrist watches, smartphones, reading material, and so forth. The experimenter then told the participant that they needed to deal with some technical issues in another room, but that they would come back soon to start with the task. This is when the 7.5-min-long waiting task started. After the experimenter came back, participants were told to fill out a series of questionnaires related to the waiting situation.

The study by Witowska et al. (2020) showed that boredom and arousal correlate significantly both with the feeling of time passing more slowly and with more frequent thoughts about time. In addition, the study showed that boredom mediates the relationship between self-regulation and time perception. Those participants with a higher tendency to self-regulate were less bored and experienced time as passing faster and, conversely, those with a lower tendency to self-regulate were more bored and as a result experienced time as passing more slowly.

The study by Witowska et al. (2020) was the second of its kind, the first being conducted by Jokic et al. (2018). In this prior study, participants also waited for $7.5 \mathrm{~min}$ in a room devoid of interesting stimuli. The results show that time perception is influenced by states like relaxation and traits like impulsivity or present orientation. The more relaxed participants felt that time passed faster and vice versa. Participants who were more impulsive and with stronger present orientation experienced the waiting time as passing more slowly and, in contrast, participants with a future orientation felt that time passed faster.

A recent study by Ehret et al. (2020) showed that high time awareness and a slow subjective passage of time do not necessarily correlate with negative valence. The participants spent time inside two different libraries. In one condition they were instructed to explore and in the other to wait sitting down. Although the results show that some participants reported the typical combination of high time awareness with negative valence and low time awareness with positive valence, a group of participants (mostly in the sitting condition) reported high time awareness with positive valence. According to the authors, achieving this latter state of idleness hinges on the capacity to accept the constraints of the situation, similarly to a mindful attitude.

This is part of a series of studies within the VIRTUALTIMES project that explore how virtual environments affect time perception to inform the design of the therapeutic VR environment. Here, we focused on subjective time in a VR waiting situation as it is related to affective states such as boredom. We also assessed the effects of individual differences for self-regulation as a trait influencing subjective time during the waiting situation. We hypothesized that, like in the real waiting situation (Witowska et al., 2020), the experience of boredom would lead to more frequent thoughts about time and a slower subjective passage of time. The propensity for higher self-regulation was expected to counteract the feeling of boredom and lead to less time awareness. As VR is an interesting, novel technology, we hypothesized that participants would be less bored in the virtual waiting room and therefore experience a faster passage of time than in the real room.

\section{Method}

\section{Materials \\ Virtual Reality}

The VR waiting room was developed for this experiment at IGPP with Unreal Engine (version 4.24). It was designed after the real room where the study by Witowska and colleagues took place. We therefore respected the proportions of the room, the placement and 
type of furniture and decoration, and the light sources. The virtual room was decorated with assets from the packs Furniture Collection by Big Stake Games, the Houseplant Pack by IanRoach, and the Framed Photography Pack by Scanning Reality, all bought at the Unreal Marketplace. Two of the photos hanged on the virtual walls were digitized versions of those in the real room. Because these photographs hang on the wall right next to the place where participants were sitting in the real study, we deemed it important to have the exact same images hanging on the equivalent wall in the virtual space. The other photos are further away and have less evocative, abstract motifs, so we used images provided with the purchased assets. Although both rooms were not identical in every detail, the resemblance is clearly noticeable (Figure 1). We did not use an avatar for the virtual room, meaning that the participants had no virtual body.

After the waiting time, participants interacted with the First Steps and First Contact VR experiences from Oculus, which are short interactive scenes meant to introduce players to the basics of virtual reality, especially with respect to the use of controllers. First Steps is designed explicitly as a tutorial, with a voice over guiding the player through the experience and explaining the different functionalities of the buttons. The scene is an abstract environment similar to those in the movie Tron. First Contact can be played independently, but it is also automatically launched after finishing First Steps. This scene is set inside a retrofuturistic environment reminiscent of the esthetics of the 1980s, where an expressive floating robot gives players a few simple activities. Among other things, these scenes teach players how to press buttons, grab and throw objects, and shoot a virtual toy gun with their virtual hands. We used the same questionnaires as with the waiting room to collect data on the experience of these scenes.

Video of the waiting room experience was captured with the software Plays.tv at first, and later with GeForce Experience because the former was discontinued and deactivated by the developer during the course of the experiment. This video footage was recorded to check afterward if the participants followed the instructions because we would be able to detect if they stood up or removed the headset from the movements of the image.

To run the virtual experiences we used a Windows 10 PC with an Intel i7-9700 K processor, $16 \mathrm{~GB}$ of RAM, and a GeForce RTX 2080Ti with an Oculus Rift S head-mounted display (HMD). While experiencing the VR waiting room, participants sat on a chair that resembled the one in the VR setting and because they were sitting at a virtual table, we also provided a small (real) table for participants to rest their arms on. Otherwise, seeing the virtual table would have generated the expectation that you can rest your arms on it, disagreeing with the experience of not feeling a table in reality. Because the VR room was not interactive in any way except for the ability to look around with the headset, participants were not given controllers. First Steps and First Contact were experienced standing up and with the Oculus controllers. We created an instruction sheet to briefly explain participants how to operate the Oculus Touch controllers prior to these experiences.

\section{Questionnaires}

We used an information sheet, a consent form, and questionnaires assessing both states and traits as used in the study by Witowska et al. (2020). The first questionnaire asked if they were able to take part in the experiment, if they were not under the influence of any substances, when they ate for the last time, and if they were well rested.

We also used two subscales of The Scales for Experiencing Emotions (SEE): emotion regulation and self-control (Behr \& Becker, 2012). They consist of a list of 10 statements like "I know ways to control my emotional states" or "I am always in control of myself." Participants need to report if the statements are true or false on a 5-point Likert scale (from $1=$ completely false to 5 = completely true).

The Self-Assessment Mannequin (SAM; Bradley \& Lang, 1994) was used to assess two states: valence (negative to positive) and arousal (how excited or calm they were). To this end, SAM uses two questions, each of which has to be answered by choosing the most valid option from a set of five pictures of an abstracted human figure that represent the different states. Question one asks how positively or negatively they feel and the figures range from a sad face, through a neutral face, to a happy face. Question two asks how calm or excited they are and the figures range from a version with closed eyes and a dot on the chest to a version with fully opened eyes and a spiked, explosion-like shape on the chest.

We also used the same version of the Inventory on Subjective Time, Self, Space (STSS) used by Witowska et al. (2020). This version of the STSS asks how long the task lasted with a 130-mm visual-analog scale (VAS) divided into 10-mm (1-cm) segments,

\section{Figure 1}

Left: Photo of the Real Waiting Room. Right: Screen Capture of the Virtual Reality (VR) Waiting Room
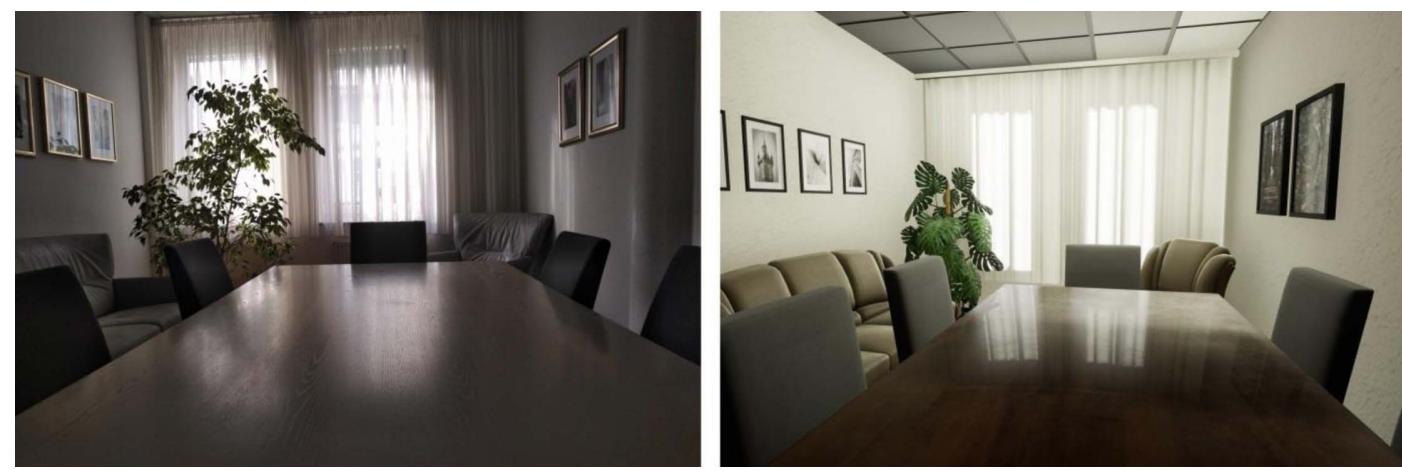
representing $13 \mathrm{~min}$ in total. Participants need to indicate with a vertical line how long they thought that the time interval (e.g., waiting) lasted (duration estimation). The STSS also uses 100-mm VAS to assess how often participants thought about time, from not at all to extremely often; how fast time passed for them, from extremely slowly to extremely fast. In addition, a VAS assessed how bored they felt during that time, from not bored at all to extremely bored.

\section{Participants}

In total, 83 participants took part in the experiment ( 49 women, 34 men), who were mostly students from the University of Freiburg. ${ }^{1}$ They were recruited through online university portals, by word of mouth, and from other experiments taking place at the institute. There was no significant difference concerning the number of male and female participants, $\chi^{2}=2.771, p=.100$. The average age was of 24.7 years $(S D=3.58)$. Almost half of the participants $(48.2 \%)$ had never had an experience with VR before the experiment, $28.9 \%$ had tried VR once, $13.3 \%$ twice, $8.4 \%$ three times, and $1.2 \%$ more than three times. The level of education was overall high, with $48.2 \%$ of the participants having a university degree (coded as 4 ), $48.2 \%$ a high school diploma (the German "Abitur" or "Fachabitur"; 3), $1.2 \%$ a "Realschulabschluss" (2), and 2.2\% a "Hauptschulabschluss" (1), the latter two are German school diplomas that do not grant access to university education.

The study conducted by Witowska et al. (2020) in the real waiting room had a sample of 97 participants of which 65 were women and 32 men. There was no significant difference in the distribution of sex between the two studies, $\chi^{2}=1.225, p=.268$. The average age in Witowska and colleagues' study (2020) was of 23.86 years $(S D=3.35)$. There was no significant difference between the average age in this and our VR study, $t(178)=1.65, p=.12$. Participants in the real waiting room study had overall a slightly but significantly lower level of education $(M=3.2)$ than participants in the VR waiting room study, $M=3.4 ; t(178)=2.55$, $p=.012$. Of note, $22.7 \%$ of the participants in Witowska et al.'s study had a university degree, $75.3 \%$ a high school diploma ("Abitur" or "Fachabitur"), and 2.1\% had a "Realschulabschluss." In both studies we recruited most subjects through the university. By chance, students in the real waiting room study were more often studying for a bachelor's degree, while in the VR waiting room study we had more students pursuing a master's degree (i.e., already with a bachelor's degree). Regarding the SEE, there was a tendency for individuals in the VR study (mean emotion regulation: 13.35; mean self-control: 20.23) to have slightly higher values than participants in the real waiting study (emotion regulation: 12.59; self-control: 19.03); emotion regulation: $t(178)=1.84, p=.063$; self-control: $t(178)=1.96, p=.052$.

The study was approved by the local Ethics Committee, for the waiting time study protocol by IGPP-2018-03 and for the VR setting by IGPP-2019-01.

\section{Procedure}

When participants arrived at the institute, they were asked to hand in their watches and smartphones. They sat at the small table prepared for the study, read the information sheet, and read and signed the consent form. We assessed their current state through the questionnaire that determines if they can take part in the experiment. Then participants filled out the SEE.

After that participants were handed the VR headset. The experimenter showed them how to properly adjust it so that it would sit comfortably and steadily on their head. Then, the experimenter launched the VR room and started recording video of what the participants were looking at (screen capture). The experimenter stayed in the room for a minute while the participants adjusted to the VR environment so that some of the potential novelty effect would wear off (at least to some degree). During this time, the experimenter would also provide help if the participants had any questions or complaints about the headset. After the minute was over, the experimenter said that they needed to go to another room to make some configurations so that an alleged game would start. This was a misleading statement because the participants had to wait for $7.5 \mathrm{~min}$ for the experimenter to come back. While leaving the room, the experimenter asked the participant to remain sitting down and with the headset on until they came back. Once outside and with the door shut behind them, the experimenter started a countdown of $7.5 \mathrm{~min}$. Table 1 offers a comparison between the methods used in the real waiting room study and the methods used in the VR waiting room study.

When the countdown finished, the experimenter returned to the room and informed the participant that the task was over. The participant could then remove the headset and answer the SAM and STSS questionnaires. The experimenter then showed the participant how to use the controllers with the aid of the instruction sheet. The participant held one controller with their dominant hand and the experimenter used the other one to explain how to operate it. After this, the table and chair were moved to the side because First Steps and First Contact are played standing up. The participant put once again the headset on, and was given both controllers.

The experimenter started First Steps and remained in the room until they reached a very early section of the game where they need to press a button with their digital index finger, which had caused some confusion to players in a pilot study. In this way, we could also make sure that the participant had understood how to use the controllers correctly. The experimenter let the participant know that they were leaving the room and, once outside, they set again a 7.5-min countdown. After the $7.5 \mathrm{~min}$, the experimenter came back and stopped the experience. Participants were then asked to fill out again the SAM and STSS questionnaires.

\section{Statistical Analysis}

To compare the results concerning time perception and emotional states in the VR and real-world waiting situations, we ran independent two-sample $t$ tests. Pearson correlation coefficients were calculated for between-item associations. Due to the multiple comparisons problem, we corrected the $\alpha$ value according to

\footnotetext{
${ }^{1}$ Initially we intended to recruit $n=100$ subjects, similarly to the study by Witowska et al. (2020). Due to the COVID-19 pandemic and the consequent regulations we had to stop recruitment and testing when we had $n=83$ subjects. Because in our first waiting room study (Jokic et al., 2018) we had $n=82$ subjects, we know that the effect sizes of the used variables are sufficient to detect significant correlations among them. Given the significant correlation coefficients of around 0.3 in Jokic et al. (2018), assuming onetailed calculations for associations (the sign of the coefficients is known), using a standard power of 0.8 a number of 67 participants are required to reach a $p$ value of .05 .
} 
Table 1

Comparison Between the Real Waiting Room and the VR Waiting Room Studies

\begin{tabular}{|c|c|c|}
\hline Study constraints & Real waiting room & VR waiting room \\
\hline$n$ & 97 & 83 \\
\hline Participant instructions & $\begin{array}{l}\text { Participants were told that there were technical } \\
\text { problems that caused a delay with the } \\
\text { participant before them. The experimenter } \\
\text { apologized and asked the participant to wait } \\
\text { for them to come back }\end{array}$ & $\begin{array}{l}\text { Participants were told that the game needed to } \\
\text { be started from another room. The } \\
\text { experimenter asked the participant to wait } \\
\text { sitting down and with the headset on until } \\
\text { they came back }\end{array}$ \\
\hline Room & $\begin{array}{l}\text { Waiting room at the Institute for Frontier Areas } \\
\text { of Psychology and Mental Health }\end{array}$ & $\begin{array}{l}\text { VR replica of the physical waiting room created } \\
\text { with Unreal Engine } 4 \text { and experienced with } \\
\text { an Oculus Rift S HMD }\end{array}$ \\
\hline Waiting time & $7.5 \mathrm{~min}$ & $7.5 \mathrm{~min}$ \\
\hline Questionnaires & $\begin{array}{l}\text { - STSS (time estimation, passage of time, } \\
\text { thinking about time) } \\
\text { - SAM (valence and arousal) } \\
\text { - Level of relaxation ("How relaxed did you feel } \\
\text { most of the time?") } \\
\text { - Level of boredom ("How bored did you feel } \\
\text { most of the time?") } \\
\text { - SEE (emotion regulation and self-control) } \\
\text { - Temporal metacognition scale }\end{array}$ & $\begin{array}{l}\text { - STSS (time estimation, passage of time, } \\
\text { thinking about time) } \\
\text { - SAM (valence and arousal) } \\
\text { - Level of boredom ("How bored did you feel } \\
\text { most of the time?") } \\
\text { - SEE (emotion regulation and self-control) }\end{array}$ \\
\hline
\end{tabular}

Note. $\quad$ VR $=$ virtual reality; HMD $=$ head-mounted display; STSS $=$ subjective time, self, space; SAM = self-assessment mannequin; SEE $=$ scales for experiencing emotions.

Bonferroni with an initial $p$ value set to .05 . We used Cohen's $d$ (Cohen, 1988) to calculate the effect sizes.

Because the order of the conditions (VR waiting vs. playing) was not balanced-for comparison with the waiting room study we had to start with the waiting room scenario-we did not compare waiting and playing but analyzed the two situations independently.

The data are available at https://doi.org/10.17605/OSF.IO/3AKM7

\section{Results}

\section{Correlations in the VR Waiting Room}

\section{Subjective States and Time Perception}

Two time variables assessed with the STSS correlated between each other, in that the more the participants thought about time, the slower time passed for them $(r=-.338, p=.002)$; there was only a tendency for a relation showing that the more subjects thought about time the longer was their judgment of duration $(r=.221, p=.045)$.
No relation was found between the duration estimate and the subjective passage of time $(r=-.115, p=.300)$.

Regarding time perception and affective states, several correlations were significant (see Table 2): The better the participants felt during the waiting time (SAM valence), the faster time passed for them $(r=.513 ; p<.001)$. The more boredom participants reported, the more they thought about time $(r=.318, p=.003)$ and the slower time passed for them $(r=-.486, p<.001)$. Between boredom and duration estimation we found no significant correlation $(r=.122$, $p=.270)$. The Bonferroni-corrected $p$ value for the reported 12 correlations among the state variables lies at .00417 .

\section{Influence From Traits: Emotion Regulation and Self-Control}

After $\alpha$ adjustment, there are no significant correlations between the variables of emotion regulation and self-control with the state

Table 2

Correlations: State and Time-Related Variables in VR While Waiting

\begin{tabular}{|c|c|c|c|}
\hline Variables & $\begin{array}{l}\text { How much time did you spend } \\
\text { in the waiting room? }\end{array}$ & $\begin{array}{c}\text { How often did you think } \\
\text { about time? }\end{array}$ & $\begin{array}{l}\text { How fast did time pass } \\
\text { for you? }\end{array}$ \\
\hline \multicolumn{4}{|c|}{ SAM pleasure } \\
\hline$-\mathrm{r}$ & -.216 & -.235 & $.513^{\mathrm{a}}$ \\
\hline$-\mathrm{p}$ & .049 & .033 & $<.001$ \\
\hline \multicolumn{4}{|c|}{ SAM arousal } \\
\hline$-r$ & -.035 & -.123 & -.014 \\
\hline$-\mathrm{p}$ & .752 & 269 & .901 \\
\hline \multicolumn{4}{|c|}{ How bored were you? } \\
\hline$-r$ & .122 & $.318^{\mathrm{a}}$ & $-.486^{\mathrm{a}}$ \\
\hline$-\mathrm{p}$ & .270 & .003 & $<.001$ \\
\hline
\end{tabular}

Note. $\mathrm{VR}=$ virtual reality; $\mathrm{SAM}=$ self-assessment mannequin. Values in bold indicate significant results.

a significant correlation after Bonferroni adjustment. 
variables; a tendency of an association is seen for self-control which positively correlated with the passage of time $(r=.247, p=.050)$.

\section{VR Versus Real Waiting Room}

Although the results concerning affective states and time perception showed the same tendencies as in the Witowska et al.'s (2020) study, we found significant differences between the waiting situation in VR and the real room in two variables: Participants felt that the passage of time was significantly slower, $t(178)=-3.245$, $p=.001$, and were significantly more bored, $t(178)=2.670$, $p=.008$, in the VR condition. These differences remained significant after Bonferroni correction. As shown in Table 3, the other variables (SAM pleasure, SAM arousal, duration estimation, thinking about time) did not show significant differences between the studies. The distributions of subjective estimated durations for the VR and real waiting rooms are shown in Figure 2.

\section{Correlations Among Affective States in the Playing Time}

During the 7.5-min-long playing time (First Steps and First Contact) we found several similar significant correlations to the waiting time (all Bonferroni corrected if not indicated; for $n=12$ correlations, $p=0.00417$; see Table 4). The more positive participants felt (SAM valence) during this time, the less they thought about time ( $r=-.507$, $p<.001)$ and the faster they experienced the passage of time $(r=.418, p<.001)$. The more boredom participants reported, the more they thought about time $(r=.407, p<.001)$ and the more slowly time passed in their experience $(r=-.418, p<.001)$. Among the three time variables, thinking more often about time marginally correlated with a slower passage of time $(r=-.267, p=.015$; not significant after Bonferroni adjustment).

Similar to the VR waiting situation, the variables of emotion regulation and self-control did not correlate significantly with the state variables for the playing condition (all $p>0.05$ ).
Figure 2

Distribution of Subjective Estimated Durations for the VR (Upper Plot) and Real (Lower Plot) Waiting Rooms
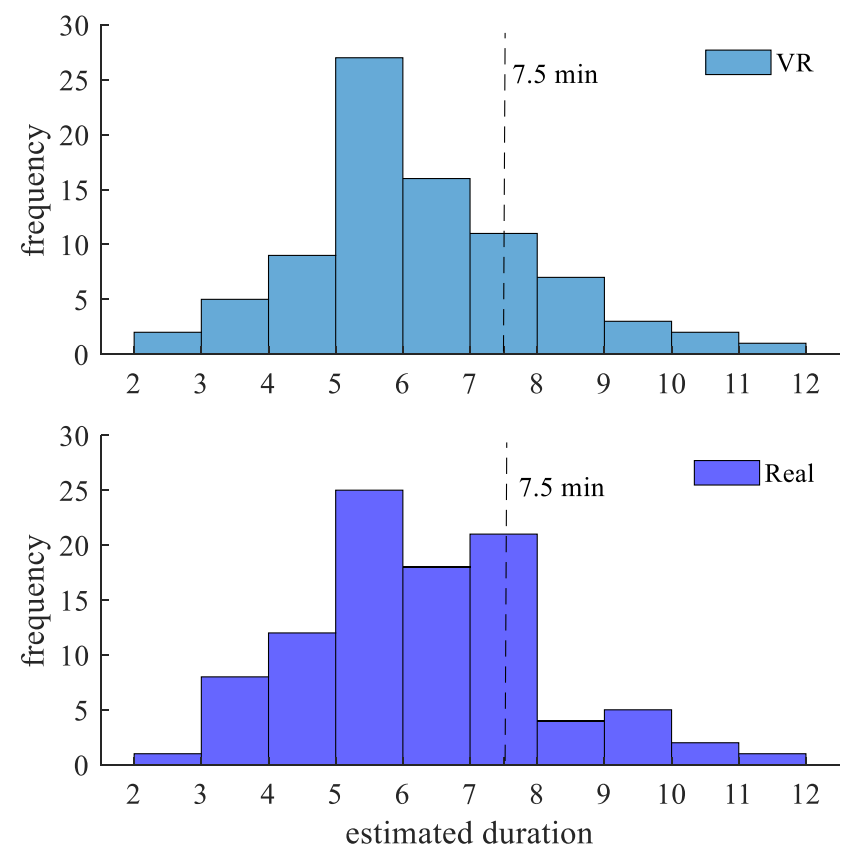

Note. The dashed line indicates the $7.5 \mathrm{~min}$ of actual waiting time. VR $=$ virtual reality.

\section{Discussion}

This study assessed the relation between the perception of the passage of time, boredom, and self-regulation in a VR waiting room. In addition, it assessed how individuals react to a gameplay session of the same duration. The results of this study are coherent with Zakay and Block's (1997) attentional-gate model in that participants

Table 3

Differences Between the VR and Real Waiting Times (W)

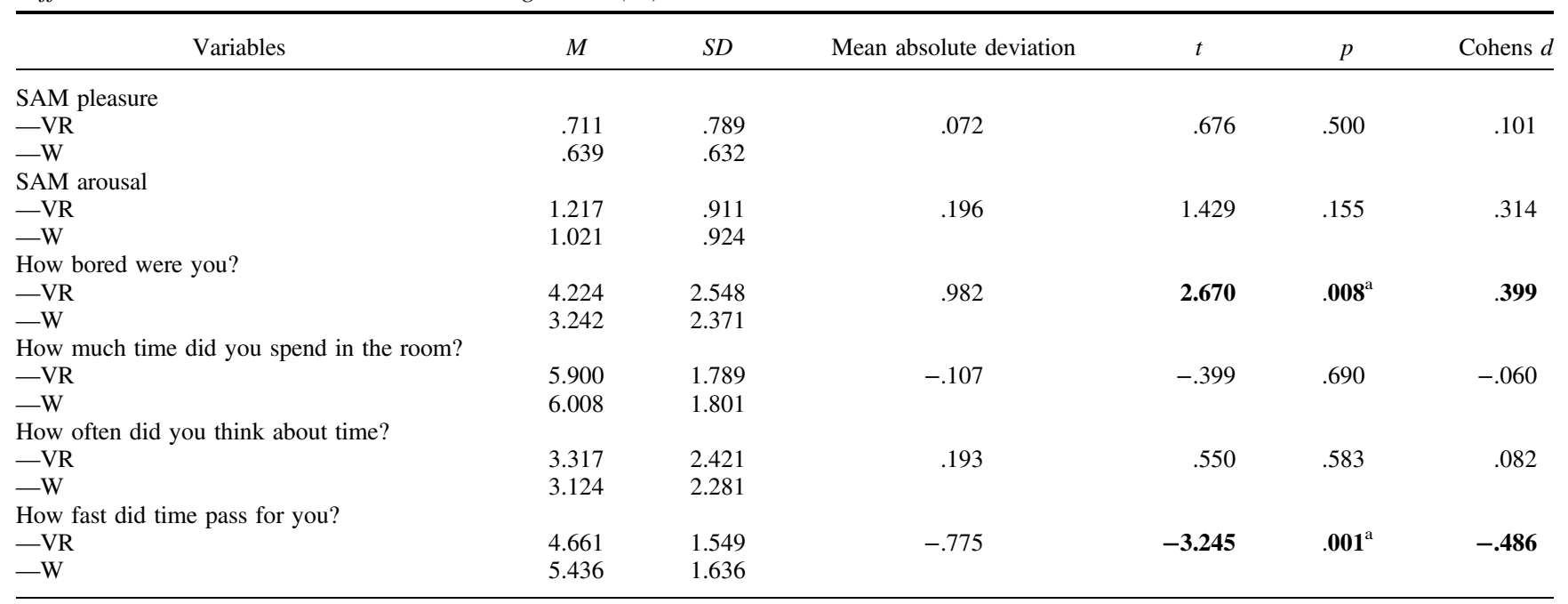

Note. $\quad \mathrm{VR}=$ virtual reality; $\mathrm{SAM}=$ self-assessment mannequin. Significant parameters marked in bold.

${ }^{\text {a }}$ Bonferroni adjusted for $n=6$ statistical tests; $p=.0083$. 
Table 4

Correlations: State and Time-Related Variables in VR While Playing

\begin{tabular}{|c|c|c|c|}
\hline Variables & $\begin{array}{l}\text { How much time did you spend } \\
\text { in the waiting room? }\end{array}$ & $\begin{array}{l}\text { How often did you think } \\
\text { about time? }\end{array}$ & $\begin{array}{l}\text { How fast did time pass } \\
\text { for you? }\end{array}$ \\
\hline \multicolumn{4}{|c|}{ SAM pleasure } \\
\hline$-\mathrm{r}$ & .127 & $-.507^{\mathrm{a}}$ & $.418^{\mathrm{a}}$ \\
\hline$-\mathrm{p}$ & .252 & $<.001$ & $<.001$ \\
\hline \multicolumn{4}{|c|}{ SAM arousal } \\
\hline$-\mathrm{r}$ & -.083 & -.165 & .163 \\
\hline$-\mathrm{p}$ & .455 & .135 & .141 \\
\hline \multicolumn{4}{|c|}{ How bored were you? } \\
\hline$-\mathrm{r}$ & -.044 & .407 & $-.418^{\mathrm{a}}$ \\
\hline$-\mathrm{p}$ & .693 & $<.001$ & $<.001$ \\
\hline
\end{tabular}

Note. $\quad \mathrm{VR}=$ virtual reality; $\mathrm{SAM}=$ self-assessment mannequin. Values in bold indicate significant results.

a significant correlation after Bonferroni adjustment.

who were more bored paid more attention to time and experienced a slower passage of time. More specifically, the study partly confirmed the findings of the previous study by Witowska et al. (2020), which had participants wait in a real waiting room, in a VR version of the same room. Like Witowska et al. (2020), we found that the more bored participants were, the more they thought about time and the more slowly time passed in their experience. We also found that participants for whom the waiting period was more pleasant thought less about time, experienced a faster passage of time, and estimated the waiting time to be shorter. But, although these correlations were similar to those in the Witowska and colleagues study (2020), we found that participants in our study were even more bored and experienced an even slower passage of time. In other words, the VR waiting room experience was more tedious than the real waiting room experience.

We originally expected the VR room to be more interesting and thus less boring than the real room because even simple VR environments can be exciting due to their immersive capabilities, especially to first timers. The results show that the technology not only failed to mitigate the effects of an uninteresting environment but also that it increased them on the two variables of boredom and passage of time.

The outcome of the VR room being more boring than the real one may be explained in terms of the participants' expectations. A VR room sets different expectations than a real room, given that virtual environments are most commonly used for entertainment. Practically anything could happen in a virtual world, so the participants' expectations may have reflected this potentiality. In the real waiting room, participants could not have expected much to happen-other than the experimenter coming back. The contrast between what was expected and what actually happened (or did not happen, to be more precise) might have made the experience of the VR waiting room more boring than the real one. Because we did not assess the participants' expectations, we can only speculate.

Unlike the Witowska et al.'s study (2020), we could not find correlations between emotion regulation or self-control and the time-related variables of duration estimation, passage of time, and thinking about time. Given that we regularly encounter waiting situations, we learn to use coping mechanisms and intuitively apply them when faced with empty time. Participants may not have known how to react to the VR waiting situation due to its novelty and therefore may not have applied the same coping strategies they would in a real waiting situation. This could explain why we found no correlation between emotion regulation or self-control and the experience of the passage of time.

A few limitations should be noted. First, we did not use an avatar. Having a representation of the participants' body in the virtual space could have an impact in the results, as suggested by the preliminary study conducted by Lugrin et al. (2019). Second, we did not control for luminance differences between the real and VR waiting rooms. Potential differences in brightness (i.e., a higher luminance in the real waiting room) may have influenced the participants' experience of time. These two aspects should be taken into account in future studies. Third, we slightly changed the instructions that Witowska et al. (2020) gave participants before the waiting time. While in the real waiting room study participants were told to wait for the experimenter to come back so that the experiment would start, participants in the VR study were told to wait for a game to start. The expectation of a game starting may have had a different effect on the participants' experience of time compared to the expectation that an experiment would start

After the waiting situation, participants played the VR games First Steps and First Contact. Similar correlations between affective states and time perception were disclosed. More enjoyment (less boredom) led to a state where participants thought less about time and felt that time passed more quickly.

In a state of flow time accelerates and in a state of boredom time decelerates in experience. Thus, the experience of the passage of time seems to be a good indicator of the enjoyment of an event. This appears to be especially true of video games and virtual environments. Video games have been shown to be highly effective at accelerating the passage of time (Bisson et al., 2012; Bisson \& Grondin, 2013; Luthman et al., 2009; Rau et al., 2006; Tobin et al., 2010; Tobin \& Grondin, 2009; Wood et al., 2004), but here we show the first evidence that a boring virtual environment devoid of contextual changes was more effective than a real one at decelerating the passage of time.

The findings in this study could inform the design of virtual experiences, especially those aimed at improving mental health, such as the VIRTUALTIMES project within which this study was conducted. Isacescu et al. (2017, p. 2) pointed out that "being disengaged from one's environment may be a precursor to both boredom and depression." Accordingly, depression has been interpreted as resulting from of a desynchronization of an individual and 
the environment or society (Fuchs, 2001). Although depression is certainly a much worse affliction than a transitory state like boredom, depressed patients tend to report a dragging passage of time (Vogel et al., 2018) and direct attention inward (Nolen-Hoeksema, 2000), as do bored individuals to a lesser degree. Kühn et al. (2018) showed that individuals with depression disorder who played the commercial game Boson $X$ regularly for 6 weeks experienced a decrease in symptoms like rumination. Engaging with timeaccelerating video games may be a way to help patients deal with this mental illness. As mentioned before, some video games have been designed with the purpose of enhancing the regulation of emotions such as anxiety (Barnes \& Prescott, 2018; Scholten et al., 2016; Schoneveld et al., 2016; Villani et al., 2018), and expose patients to anxiety-inducing scenarios to train their coping skills. Exposing individuals with psychopathological symptoms to virtual waiting situations in a therapeutic context might help enhance their emotion regulation in these situations.

\section{Conclusion}

This is, after Jokic et al. (2018) and Witowska et al. (2020), the third study to show the relation between waiting situations and a slower subjective passage of time, though this time in a virtual room. These studies lend credence to the idiom "a watched pot never boils." While we wait for something to happen, we focus on the passage of time and the moment stretches in our experience.

In this study, we show for the first time that a VR environment devoid of interesting stimuli can not only be boring but also can be even more boring and slow down the experience of the passage of time more than its real counterpart. We also found that boredom correlates with how often participants think about time and how slow time passes in their experience during the waiting time. Conversely, the more pleasant the experience is, the less bored participants are, the less they think about time and the faster time passes in their experience.

\section{References}

Alvarez Igarzábal, F. (2019). Time and space in video games: A cognitiveformalist approach. Transcript. https://doi.org/10.14361/9783839447130 Alvarez Igarzábal, F. (2020). Experiencing the passage of time in video games. Philosophy of Computer Games 2019, St. Petersburg, Russia. http://gamephilosophy.org/conference-manuscripts/

Angrilli, A., Cherubini, P., Pavese, A., \& Mantredini, S. (1997). The influence of affective factors on time perception. Perception \& Psychophysics, 59(6), 972-982. https://doi.org/10.3758/BF03205512

Bansal, A., Weech, S., \& Barnett-Cowan, M. (2019). Movement-contingent time flow in virtual reality causes temporal recalibration. Scientific Reports, 9(1), Article 4378. https://doi.org/10.1038/s41598-019-40870-6

Bar-Haim, Y., Kerem, A., Lamy, D., \& Zakay, D. (2010). When time slows down: The influence of threat on time perception in anxiety. Cognition and Emotion, 24(2), 255-263. https://doi.org/10.1080/02699930903387603

Barnes, S., \& Prescott, J. (2018). Empirical evidence for the outcomes of therapeutic video games for adolescents with anxiety disorders: Systematic review. JMIR Serious Games, 6(1), Article e3. https://doi.org/10 .2196/games.9530

Baumeister, R. F., \& Heatherton, T. F. (1996). Self-regulation failure: An overview. Psychological Inquiry, 7(1), 1-15. https://doi.org/10.1207/ s15327965pli0701_1
Baumeister, R. F., Vohs, K. D., \& Tice, D. M. (2007). The strength model of self-control. Current Directions in Psychological Science, 16(6), 351355. https://doi.org/10.1111/j.1467-8721.2007.00534.x

Behr, M., \& Becker, M. (2012). Scales for experiencing emotions: Awareness, appraisal and regulation of one's own emotions. Hellenic Journal of Psychology, 9(3), 278-303.

Bisson, N., \& Grondin, S. (2013). Time estimates of internet surfing and video gaming. Timing \& Time Perception, 1(1), 39-64. https://doi.org/10 $.1163 / 22134468-00002002$

Bisson, N., Tobin, S., \& Grondin, S. (2012). Prospective and retrospective time estimates of children: A comparison based on ecological tasks. PLOS ONE, 7(3), Article e33049. https://doi.org/10.1371/journal.pone.0033049

Botella, C., Fernández-Álvarez, J., Guillén, V., García-Palacios, A., \& Baños, R. (2017). Recent progress in virtual reality exposure therapy for phobias: A systematic review. Current Psychiatry Reports, 19(7), Article 42. https://doi.org/10.1007/s11920-017-0788-4

Bowman, N. D., \& Tamborini, R. (2012). Task demand and mood repair: The intervention potential of computer games. New Media \& Society, 14(8), 1339-1357. https://doi.org/10.1177/1461444812450426

Bradley, M. M., \& Lang, P. J. (1994). Measuring emotion: The selfassessment manikin and the semantic differential. Journal of Behavior Therapy and Experimental Psychiatry, 25(1), 49-59. https://doi.org/10 .1016/0005-7916(94)90063-9

Cohen, J. (1988). Statistical power analysis for the behavioral sciences (2nd ed.). Lawrence Erlbaum.

Coyle, D., McGlade, N., Doherty, G., \& O'Reilly, G. (2011). Exploratory evaluations of a computer game supporting cognitive behavioural therapy for adolescents. In Proceedings of the 2011 annual conference on human factors in computing systems - CHI '11 (pp. 2937-2946). Association for Computing Machinery. https://doi.org/10.1145/1978942.1979378

Csikszentmihalyi, M. (2000). Beyond boredom and anxiety (25th anniversary ed.). Jossey-Bass.

Csikszentmihalyi, M. (2009). Flow: The psychology of optimal experience. Harper and Row.

Csikszentmihalyi, M. (2014). Flow and the foundations of positive psychology. Springer. https://doi.org/10.1007/978-94-017-9088-8

Deng, W., Hu, D., Xu, S., Liu, X., Zhao, J., Chen, Q., Liu, J., Zhang, Z., Jiang, W., Ma, L., Hong, X., Cheng, S., Liu, B., \& Li, X. (2019). The efficacy of virtual reality exposure therapy for PTSD symptoms: A systematic review and meta-analysis. Journal of Affective Disorders, 257, 698-709. https://doi.org/10.1016/j.jad.2019.07.086

Droit-Volet, S., Brunot, S., \& Niedenthal, P. (2004). Perception of the duration of emotional events. Cognition and Emotion, 18(6), 849-858. https://doi.org/10.1080/02699930341000194

Ehret, S., Trukenbrod, A. K., Gralla, V., \& Thomaschke, R. (2020). A grounded theory on the relation of time awareness and perceived valence. Timing \& Time Perception (Leiden, Netherlands), 8(3-4), 316-340. https://doi.org/10.1163/22134468-bja10014

Ferguson, C. J., \& Rueda, S. M. (2010). The hitman study: Violent video game exposure effects on aggressive behavior, hostile feelings, and depression. European Psychologist, 15(2), 99-108. https://doi.org/10 $.1027 / 1016-9040 / \mathrm{a} 000010$

Fisher, C. D. (1993). Boredom at work: A neglected concept. Human Relations, 46(3), 395-417. https://doi.org/10.1177/001872679304600305

Fuchs, T. (2001). Melancholia as a Desynchronization: Towards a Psychopathology of Interpersonal Time. Psychopathology 34(4), 179-186. https://doi.org/10.1159/000049304

Giakoumis, D., Tzovaras, D., Moustakas, K., \& Hassapis, G. (2011). Automatic recognition of boredom in video games using novel biosignal moment-based features. IEEE Transactions on Affective Computing, 2(3), 119-133. https://doi.org/10.1109/T-AFFC.2011.4

Gil, S., Niedenthal, P. M., \& Droit-Volet, S. (2007). Anger and time perception in children. Emotion, 7(1), 219-225. https://doi.org/10.1037/ 1528-3542.7.1.219 
Hofmann, W., Rauch, W., \& Gawronski, B. (2007). And deplete us not into temptation: Automatic attitudes, dietary restraint, and self-regulatory resources as determinants of eating behavior. Journal of Experimental Social Psychology, 43(3), 497-504. https://doi.org/10.1016/j.jesp.2006 .05 .004

Hussain, Z., \& Griffiths, M. D. (2009). The attitudes, feelings, and experiences of online gamers: A qualitative analysis. Cyberpsychology \& Behavior, 12(6), 747-753. https://doi.org/10.1089/cpb.2009.0059

Isacescu, J., Struk, A. A., \& Danckert, J. (2017). Cognitive and affective predictors of boredom proneness. Cognition and Emotion, 31(8), 17411748. https://doi.org/10.1080/02699931.2016.1259995

Jokic, T., Zakay, D., \& Wittmann, M. (2018). Individual differences in selfrated impulsivity modulate the estimation of time in a real waiting situation. Timing \& Time Perception, 6(1), 71-89. https://doi.org/10 $.1163 / 22134468-00002101$

Kühn, S., Berna, F., Lüdtke, T., Gallinat, J., \& Moritz, S. (2018). Fighting depression: Action video game play may reduce rumination and increase subjective and objective cognition in depressed patients. Frontiers in Psychology, 9, Article 129. https://doi.org/10.3389/fpsyg.2018.00129

Kuo, A., Lutz, R. J., \& Hiler, J. L. (2016). Brave new World of Warcraft: A conceptual framework for active escapism. Journal of Consumer Marketing, 33(7), 498-506. https://doi.org/10.1108/JCM-04-2016-1775

Lobel, A., Granic, I., \& Engels, R. C. M. E. (2014). Stressful gaming, interoceptive awareness, and emotion regulation tendencies: A novel approach. Cyberpsychology, Behavior, and Social Networking, 17(4), 222-227. https://doi.org/10.1089/cyber.2013.0296

Lugrin, J.-L., Unruh, F., Landeck, M., yoan, L., Latoschik, M. E., Vogeley, K., \& Wittmann, M. (2019). Experiencing waiting time in virtual reality. 25th ACM symposium on virtual reality software and technology [Symposium]. Association for Computing Machinery, New York, NY, USA. https://doi.org/10.1145/3359996.3364807

Luthman, S., Bliesener, T., \& Staude-Muller, F. (2009). The effect of computer gaming on subsequent time perception. Cyberpsychology: Journal of Psychosocial Research of Cyberspace, 3(1). Article 2. https://cyberpsychology.eu/article/view/4221/3263

Mathiak, K. A., Klasen, M., Zvyagintsev, M., Weber, R., \& Mathiak, K. (2013). Neural networks underlying affective states in a multimodal virtual environment: Contributions to boredom. Frontiers in Human Neuroscience, 7, Article 820. https://doi.org/10.3389/fnhum.2013.00820

Nolen-Hoeksema, S. (2000). The role of rumination in depressive disorders and mixed anxiety/depressive symptoms. Journal of Abnormal Psychology, 109(3), 504-511. https://doi.org/10.1037/0021-843X.109.3.504

Pollatos, O., Laubrock, J., \& Wittmann, M. (2014). Interoceptive focus shapes the experience of time. PLOS ONE, 9(1), Article e86934. https:// doi.org/10.1371/journal.pone.0086934

Rau, P.-L. P., Peng, S.-Y., \& Yang, C.-C. (2006). Time distortion for expert and novice online game players. Cyberpsychology \& Behavior, 9(4), 396403. https://doi.org/10.1089/cpb.2006.9.396

Reinecke, L., Tamborini, R., Grizzard, M., Lewis, R., Eden, A., \& David Bowman, N. (2012). Characterizing mood management as need satisfaction: The effects of intrinsic needs on selective exposure and mood repair. Journal of Communication, 62(3), 437-453. https://doi.org/10.1111/j .1460-2466.2012.01649.x

Rieger, D., Wulf, T., Kneer, J., Frischlich, L., \& Bente, G. (2014). The winner takes it all: The effect of in-game success and need satisfaction on mood repair and enjoyment. Computers in Human Behavior, 39, 281-286. https://doi.org/10.1016/j.chb.2014.07.037

Rutrecht, H., Wittmann, M., Khoshnoud, S., \& Alvarez Igarzábal, F. (2021). Time speeds up during flow states: A study in virtual reality with the video game thumper. Timing \& Time Perception. Advanced online publication. https://doi.org/10.1163/22134468-bja10033

Schatzschneider, C., Bruder, G., \& Steinicke, F. (2016). Who turned the clock? Effects of manipulated zeitgebers, cognitive load and immersion on time estimation. IEEE Transactions on Visualization and Computer
Graphics, 22(4), 1387-1395. https://doi.org/10.1109/TVCG.2016 .2518137

Schneider, S. M., Kisby, C. K., \& Flint, E. P. (2011). Effect of virtual reality on time perception in patients receiving chemotherapy. Supportive Care in Cancer, 19(4), 555-564. https://doi.org/10.1007/s00520-010-0852-7

Scholten, H., Malmberg, M., Lobel, A., Engels, R. C. M. E., \& Granic, I. (2016). A Randomized controlled trial to test the effectiveness of an immersive $3 \mathrm{D}$ video game for anxiety prevention among adolescents. PLOS ONE, 11(1), Article e0147763. https://doi.org/10.1371/journal pone. 0147763

Schoneveld, E. A., Malmberg, M., Lichtwarck-Aschoff, A., Verheijen, G. P., Engels, R. C. M. E., \& Granic, I. (2016). A neurofeedback video game (MindLight) to prevent anxiety in children: A randomized controlled trial. Computers in Human Behavior, 63, 321-333. https://doi.org/10.1016/j .chb.2016.05.005

Schuurmans, A. A. T., Nijhof, K. S., Vermaes, I. P. R., Engels, R. C. M. E., \& Granic, I. (2015). A pilot study evaluating "Dojo," a videogame intervention for youths with externalizing and anxiety problems. Games for Health Journal, 4(5), 401-408. https://doi.org/10.1089/g4h.2014.0138

Sucala, M. L., Stefan, S., Szentagotai-Tatar, A., \& David, D. (2010). Time flies when you expect to have fun. An experimental investigation of the relationship between expectancies and the perception of time progression. Cognition, Brain, Behavior: An Interdisciplinary Journal, 14(3), 231-241.

Tipples, J. (2008). Negative emotionality influences the effects of emotion on time perception. Emotion, 8(1), 127-131. https://doi.org/10.1037/15283542.8.1.127

Tobin, S., Bisson, N., \& Grondin, S. (2010). An ecological approach to prospective and retrospective timing of long durations: A study involving gamers. PLOS ONE, 5(2), Article e9271. https://doi.org/10.1371/journal .pone.0009271

Tobin, S., \& Grondin, S. (2009). Video games and the perception of very long durations by adolescents. Computers in Human Behavior, 25(2), 554-559. https://doi.org/10.1016/j.chb.2008.12.002

Treisman, M. (2013). The information-processing model of timing (Treisman, 1963): Its sources and further development. Timing \& Time Perception, 1(2), 131-158. https://doi.org/10.1163/22134468-00002017

Treisman, M., Faulkner, A., Naish, P. L. N., \& Brogan, D. (1990). The internal clock: Evidence for a temporal oscillator underlying time perception with some estimates of its characteristic frequency. Perception, 19(6), 705-742. https://doi.org/10.1068/p190705

van der Ham, I. J. M., Klaassen, F., van Schie, K., \& Cuperus, A. (2019). Elapsed time estimates in virtual reality and the physical world: The role of arousal and emotional valence. Computers in Human Behavior, 94, 77-81. https://doi.org/10.1016/j.chb.2019.01.005

Villani, D., Carissoli, C., Triberti, S., Marchetti, A., Gilli, G., \& Riva, G. (2018). Videogames for emotion regulation: A systematic review. Games for Health Journal, 7(2), 85-99. https://doi.org/10.1089/g4h.2017.0108

Vogel, D. H. V., Krämer, K., Schoofs, T., Kupke, C., \& Vogeley, K. (2018). Disturbed experience of time in depression-evidence from content analysis. Frontiers in Human Neuroscience, 12, Article 66. https://doi.org/10 .3389/fnhum.2018.00066

Watts, F. N., \& Sharrock, R. (1984). Fear and time estimation. Perceptual and Motor Skills, 59(2), 597-598. https://doi.org/10.2466/pms.1984.59 .2 .597

Wechsler, T. F., Kümpers, F., \& Mühlberger, A. (2019). Inferiority or even superiority of virtual reality exposure therapy in phobias?-A systematic review and quantitative meta-analysis on randomized controlled trials specifically comparing the efficacy of virtual reality exposure to gold standard in vivo exposure in agoraphobia, specific phobia, and social phobia. Frontiers in Psychology, 10, Article 1758. https://doi.org/10 .3389/fpsyg.2019.01758

Witowska, J., Schmidt, S., \& Wittmann, M. (2020). What happens while waiting? How self-regulation affects boredom and subjective time during a 
real waiting situation. Acta Psychologica, 205, Article 103061. https:// doi.org/10.1016/j.actpsy.2020.103061

Wittmann, M. (2015). Modulations of the experience of self and time. Consciousness and Cognition, 38, 172-181. https://doi.org/10.1016/j .concog.2015.06.008

Wittmann, M. (2018). Altered states of consciousness: Experiences out of time and self. MIT Press. https://doi.org/10.7551/mitpress/11468 .001 .0001

Wittmann, M., \& Paulus, M. P. (2008). Decision making, impulsivity and time perception. Trends in Cognitive Sciences, 12(1), 7-12. https:// doi.org/10.1016/j.tics.2007.10.004

Wood, R. T. A., Griffiths, M. D., \& Parke, A. (2007). Experiences of time loss among videogame players: An empirical study. Cyberpsychology \& Behavior, 10(1), 38-44. https://doi.org/10.1089/cpb.2006.9994

Wood, R. T. A., Gupta, R., Derevensky, J. L., \& Griffiths, M. (2004). Video game playing and gambling in adolescents: Common risk factors. Journal of Child \& Adolescent Substance Abuse, 14(1), 77-100. https://doi.org/10 .1300/J029v14n01_05

Zakay, D. (2014). Psychological time as information: The case of boredom. Frontiers in Psychology, 5, Article 917. https://doi.org/10.3389/fpsyg .2014 .00917

Zakay, D., \& Block, R. A. (1995). An attentional-gate model of prospective time estimation. In M. Richelle, V. D. Keyser, G. D. Ydeualle, \& A. Vandierendonck (Eds.), Time and the dynamic control of behavior (pp. 167-178). University of Liege Press.

Zakay, D., \& Block, R. A. (1997). Temporal Cognition. Current Directions in Psychological Science, 6(1), 12-16. https://doi.org/10.1111/1467-8721 .ep11512604

Received February 10, 2021

Revision received April 15, 2021

Accepted May 11, 2021 